\title{
Quality changes and shelf life of salted duck egg white meringues stored in alternative packages at
}

\section{two temperatures}

\author{
Paramee Noonim, Karthikeyan Venkatachalam* \\ Faculty of Innovative Agriculture and Fishery Establishment Project, Prince of Songkla University Surat Thani Campus, \\ Makham Tia, Mueang, Surat Thani 84000, Thailand
}

*Corresponding author: Karthikeyan Venkatachalam, Faculty of Innovative Agriculture and Fishery Establishment Project, Prince of Songkla University Surat Thani Campus, Makham Tia, Mueang, Surat Thani 84000, Thailand. Emails: karthikeyan.v@psu.ac.th; drkarthikeyan.v@outlook.com

Received: 26 July 2021; Accepted: 12 September 2021; Published: 6 October 2021

(c) 2021 Codon Publications

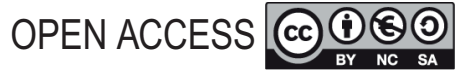

ORIGINAL ARTICLE

\begin{abstract}
Salted duck egg white meringues stored in alternative packages (paper control, metalized low-density polyethylene (M-LDPE), and polyethylene terephthalate (PET)) and at two alternative storage temperatures $\left(30^{\circ} \mathrm{C}\right.$ and $40^{\circ} \mathrm{C}$ ) were tested for changes in quality over a period of 120 days. Every 15 days, the meringues were tested for physicochemical and microbial qualities. Package type, storage temperature, and storage time all influenced the overall meringue quality. This study revealed that meringues kept at $40^{\circ} \mathrm{C}$ experienced more loss of quality than those kept at $30^{\circ} \mathrm{C}$. During storage, meringue's lightness and yellowness diminished while redness increased, and the sample volume shrunk. The control samples were significantly more affected than the other cases. The sample's weight, moisture, $\mathrm{a}_{\mathrm{w}}$, and $\mathrm{pH}$ were highest in the control samples when stored at $40^{\circ} \mathrm{C}$. Textural profiles such as hardness, chewiness, cohesiveness, fracturability, gumminess, and springiness decreased in all cases with storage time, whereas adhesiveness and resilience increased. The M-LDPE and PET packages maintained the sample texture. The radical scavenging abilities of the samples did not significantly differ by the alternatives tested, but a gradual increase was noted during prolonged storage. The control samples had significant levels of pathogenic bacteria (Escherichia coli and Salmonella) and spoilage microorganisms (yeast and mold), reducing the shelf life to 90 days. In contrast, M-LDPE and PET packages maintained the sample qualities throughout the testing period of 120 days. It was found that M-LDPE and PET packages prolonged the shelf life of meringues when stored at $30^{\circ} \mathrm{C}$, more so than at $40^{\circ} \mathrm{C}$.
\end{abstract}

Keywords: meringue; packaging; physicochemical qualities; storage; temperature

\section{Introduction}

The most traditional and popular preserved egg product in Thailand is salted duck egg, prepared by brining and/or mud coating. Thailand is well-known for its mudcoated salted duck eggs (Chi and Tseng, 1998; Lai et al., 1999). Properties of these eggs depend on the length of curing with salt. More prolonged curing could improve the taste and structure of the egg yolk, which is the main component, as it has a wide range of applications and higher economic value than the egg white, which is frequently discarded owing to extreme saltiness; this leads to economic loss and an increase in waste and pollution (Venkatachalam, 2018; Wang, 2017; Xu et al., 2017). Therefore, food products made from salted duck egg white, while avoiding expensive desalination processes, have recently become popular (Xiao et al., 2019), resulting in several food products, including meringue, noodles, and jelly products. Among the various products, meringue is one of the most straightforward products to 
adopt this new philosophy, as it uses the egg white efficiently as its primary ingredient and along with sugar, salt, acid, and flavors, followed by baking to give it additional attractiveness (Bennion et al., 1997). The egg plays a crucial role, as the quality of the foam is mainly determined by the foaming capacity and volume of the foam and the egg white's stability (Lomakina and Mikova, 2006).

Bakery items are a low to intermediate moisture commodity, often sensitive to any condition that might induce spoilage by physical, chemical, or microbiological decomposition that reduces the shelf life (Amit et al., 2017). In high moisture products, the primary issue is microbiological deterioration caused by bacteria, yeasts, and/or molds (Rawat, 2015). Many industrially produced bakery products have a surface that is essentially sterile, but post-bake handling can quickly lead to fungal and microbial surface contamination by exposure to airborne contaminants as well as by equipment contact (Saranraj and Geetha, 2012). Therefore, storage under ambient temperature is preferable for storing bakery products. The meringues can be kept at room temperature for several weeks, although it may cause color, texture, and flavor changes (Punidadas and McKellar, 1999). Food packaging can preserve food and help delay degradation, extend the shelf life, and maintain, improve, and ensure product quality and safety.

Paper packaging is typically not the best solution for protecting food for longer because it lacks barrier properties and heat stability. However, paper packaging is frequently coated and/or impregnated with materials such as wax, resin, or lacquer to improve its usefulness as a barrier (Marsh and Bugusu, 2007). On the other hand, packages made of metalized low-density polyethylene (M-LDPE) or polyethylene terephthalate (PET) are low-cost and lightweight with a variety of physical (including optical) characteristics (Andrady and Neal, 2009). In addition, plastics have varying permeability to light, gases, and vapors, which is a critical drawback in their usage. LDPE and M-LDPE, on the other hand, are two of the most widely used thermoplastic polymers in the food packaging industry. These are frequently utilized in the packaging of food, milk, and agricultural products (Bastarrachea et al., 2011), having diverse mechanical, physical, and chemical characteristics. Typically, the meringue products are stored in paper-laminated PE packages, as they are inexpensive and can have information printed on them. Yuceer and Caner (2021) observed that storing meringue products in high-density polyethylene (HDPE) package could also be able to store the meringues for up to 90 days with fewer loss in the physicochemical characteristics.

Salted duck egg white meringues are a newly developed product and have not yet been studied for shelf-life and stability. Therefore, the present study was aimed to examine the quality changes in meringue stored in alternative packages and at two storage temperatures for a prolonged period.

\section{Materials and Methods}

\section{Materials and chemical reagents}

Salted duck eggs (from 20 days of salt curing) were obtained from farmers in the Chaiya district of Surat Thani province, Thailand. The eggs were adequately cleaned and split open so that the egg white (EW) could be carefully separated for use in meringue preparation. The additional components in the recipe, including organic coconut sugar powder, pure vanilla extract, and stabilizer (cream of tartar), were acquired from a local store in Surat Thani province. Chemical and reagents such as 2, 2 -diphenyl-1-picrylhydrazyl, ferrous ammonium sulfate, tartaric acid, peptone, ethylenediamine tetra acetic acid, dimethyl sulfoxide, L-ascorbic acid, trichloroacetic acid (TCA), Nash reagent, 2,2'-azino-bis (3-ethylbenzthiazoline-6-sulphonic acid), ferrous chloride, ferrozine, ferric ammonium citrate, and ammonium sulfate were purchased from Sigma Aldrich (St. Louis, MO, USA). Ethanol was purchased from J. T. Baker (Phillipsburg, NJ, USA). Peptone, potato dextrose agar, and tryptic soy agar were purchased from HI Media Laboratory (Mumbai, India)

\section{Meringue preparation and storage}

The appropriate ingredient proportions for making meringue were established as follows: egg white (EW, $100 \%)$; coconut sugar (75\%); stabilizer (0.01\%); and food flavors $(0.01 \%)$. The EW was added to the mixing bowl and beaten using an electric kitchen mixer (RBSFOODMIXERPRO, Cuizimate, Thailand) with a $4.5 \mathrm{~L}$ stationary bowl and rotating beaters to make the meringues. The speed was set to number $4(100 \mathrm{rpm})$ for $10 \mathrm{~min}$, and during that time, the remaining components, namely, sugar, stabilizer, and food flavoring agent, were gradually added to achieve homogenous whipping and flavor dispersion. After getting homogenous whipping, the mixture was put into a pastry bag with a $3 \mathrm{~cm}$ nozzle, and a consistent cone ball shape was slowly formed on a baking pan covered with parchment paper. The meringues were then baked for $25 \mathrm{~min}$ at $163^{\circ} \mathrm{C}$ in a double stack infrared oven. Finally, the cooked meringues were allowed to cool down to room temperature before packing and storage. For packing and storing the meringue products, three alternative packages were used: polyethylene (PE)-laminated paper package (the control treatment), M-LDPE package, and PET package 
(Packaging materials used in this study were purchased from PPM Pack Co., Ltd., Thailand). In each replication, 25 meringues were included per package. The samples were securely packed and placed on a rack for 120 days at two different storage temperatures $\left(30^{\circ} \mathrm{C}\right.$ and $\left.40^{\circ} \mathrm{C}\right)$. The samples were tested for various attributes at 15-day intervals until the end of storage, as indicated below. The storage was stopped when the microbial growth exceeded the acceptable limit.

\section{Quality determinations}

\section{Measurement of color characteristics}

Color measurement of meringue surface based on CIE $L^{*}, a^{*}, b^{*}$ color system was carried out using a Hunter Colorimeter fitted with an optical sensor (AOAC, 2003).

\section{Measurement of diameter, height, and weight}

Meringue diameter and height were measured with a Vernier caliper at two places, and the average values were recorded. The weight of the meringue was measured by using a weight balance (Zoulias et al., 2000).

\section{Measurement of moisture, water activity, texture, and $\mathrm{pH}$}

The moisture contents of the cracker samples were measured using an infrared moisture analyzer (MA160, Sartorius, Germany). The water activity was measured at $25^{\circ} \mathrm{C}$ with a dew point water activity analyzer (Series 4TEV, Aqua Lab, WA, USA). Texture analysis (including hardness) of the baked meringue was assessed using a texture analyzer in a compression mode with a sharpblade cutting probe. Pretest and posttest speeds were set at $1.5,2$, and $10 \mathrm{~mm} / \mathrm{s}$, respectively. For measuring $\mathrm{pH}$, $10 \mathrm{~g}$ of sample was homogenized with $100 \mathrm{~mL}$ of distilled water and measured using a handheld digital $\mathrm{pH}$ meter (Clean, pH30, China).

\section{Texture profile analysis}

Meringue samples were tested using a texture analyzer (Texture Analyzer, model TA XT plus, Stable Micro Systems Ltd., UK) (Yuceer and Asik, 2020). The settings of the texture analyzer to measure the meringues were as follows: pretest speed $5 \mathrm{~mm} / \mathrm{s}$, test speed $1.0 \mathrm{~mm} / \mathrm{s}$, posttest speed $5 \mathrm{~mm} / \mathrm{s}$, penetration distance $10 \mathrm{~mm}$, stopping time between directions $5 \mathrm{~s}$, and trigger force 10 g. Stable Micro Systems aluminum probe (P/36R, $36 \mathrm{~mm}$ ) was used to test the texture profile. The textural profiles that included hardness, adhesiveness, chewiness, cohesiveness, fracturability, gumminess, resilience, and springiness were obtained from the Texture Exponent Software made for texture analysis.

\section{Antioxidant activities}

Meringue samples were extracted before analyzing the antioxidant activities. For extraction, a $5 \mathrm{~g}$ sample was suspended in $10 \mathrm{~mL}$ of $95 \%$ ethanol and then mixed vigorously by vortexing for $3 \mathrm{~min}$. After that, it was centrifuged at $10,000 \mathrm{~g}$ for $20 \mathrm{~min}$ at $4{ }^{\circ} \mathrm{C}$. The supernatant was collected and stored in the dark and refrigerated until analysis. For DPPH (2,2-diphenyl-1-picrylhydrazyl) radical scavenging assay (Brand-Williams et al., 1995), a $100 \mu \mathrm{L}$ aliquot was placed into a test tube containing $3.9 \mathrm{~mL}$ of $60 \mu \mathrm{mol} / \mathrm{L} \mathrm{DPPH}$ and mixed well. After that, the reaction mixture was incubated for $30 \mathrm{~min}$ in the dark at ambient temperature. Then, the reaction mixture was measured at $515 \mathrm{~nm}$ using a spectrophotometer. The results are expressed as a percentage of DPPH radical scavenging ability. For hydroxyl radical scavenging assay (Halliwell et al., 1987), a $1 \mathrm{~mL}$ aliquot was added in a test tube containing $1 \mathrm{~mL}$ of ferrous ammonium sulfate $(0.13 \%$ - Ethylenediaminetetraacetic acid (EDTA) (0.26\%) solution, $0.5 \mathrm{~mL}$ of $0.018 \%$ EDTA, $1 \mathrm{~mL}$ of $0.85 \%$ dimethyl sulfoxide, and $0.22 \%$ ascorbic acid). After that, the reaction mixture was mixed well and incubated in a water bath at $90^{\circ} \mathrm{C}$ for $10 \mathrm{~min}$. Then, the reaction was terminated by adding $1 \mathrm{~mL}$ of ice-cold TCA. After that, $3 \mathrm{~mL}$ of Nash reagent was mixed in the reaction mixture and kept at room temperature for 15 min to develop a yellow color. Then, the reaction mixture was measured at $412 \mathrm{~nm}$ using a spectrophotometer. The results are expressed as a percentage of hydroxyl radical scavenging ability. For ABTS (2,2'-azino-di-3-ethylbenzthiazoline sulfonic acid radical cation scavenging) assay, a $100 \mu \mathrm{L}$ aliquot was placed in a test tube and mixed with $100 \mu \mathrm{L}$ ABTS reagent (as described in Lee et al., 2015) in a 96-well microplate, and then it was incubated for $6 \mathrm{~min}$ at room temperature. After incubation, the sample was measured at $734 \mathrm{~nm}$ using a microplate reader. The results are expressed as a percentage of ABTS radical scavenging ability. For ferrous ion chelating activity (Singh and Rajini, 2004), a $200 \mu \mathrm{L}$ aliquot was mixed with $0.8 \mathrm{~mL}$ of $95 \%$ ethanol containing $2 \mathrm{mM} \mathrm{FeCl}_{2}$ and $5 \mathrm{mM}$ ferrozine. After that, the reaction mixture was kept at room temperature for $10 \mathrm{~min}$. Then, the absorbance of the reaction mixture was measured at $562 \mathrm{~nm}$ against a blank. A control was prepared using $0.2 \mathrm{mg}$ of EDTA in $95 \%$ ethanol. The results are expressed as a percentage of ferrous ion chelating activity.

\section{Microbiological analysis}

A 25 g sample was aseptically weighed and dissolved in $225 \mathrm{~mL}$ of sterile distilled water, followed by centrifugation at $500 \mathrm{~g}$ for $5 \mathrm{~min}$, and then the supernatant was collected, and $5 \mathrm{~mL}$ was placed into a test tube. It was diluted at 1:10 using $0.1 \%$ peptone water, followed by microbiological analysis using the pour plate method. For total plate count, $1 \mathrm{~mL}$ of diluted sample was aseptically inoculated on a Petri dish with $20 \mathrm{~mL}$ of sterilized agar (plate count agar) and mixed thoroughly. After solidification of agar, the Petri dish was inverted and incubated for $48 \mathrm{~h}$ at $30^{\circ} \mathrm{C}$. Colonies were counted and reported as 
$\log$ CFU/g (American Public Health Association, 1978). For yeast and mold, $1 \mathrm{~mL}$ of diluted sample was aseptically inoculated on a Petri dish with $20 \mathrm{~mL}$ of sterilized, acidified (using 10\% tartaric acid to adjust the $\mathrm{pH}$ to 3.5) potato dextrose agar, and mixed thoroughly. After that, the agar was allowed to solidify completely, and then the dish was incubated at $30^{\circ} \mathrm{C}$ for $48 \mathrm{~h}$. Colonies were counted and reported as $\log \mathrm{CFU} / \mathrm{g}$ (Lekjing and Venkatachalam, 2021). For Escherichia coli (E. coli), the samples were determined using Petri film E. coli Count Plate by following the AOAC (2002) method. Diluted sample $(1 \mathrm{~mL})$ was placed on the Petri film plate and left for $1 \mathrm{~min}$ to let the gel solidify, and then incubated for 2 days at $37^{\circ} \mathrm{C}$. After incubation, the colonies were counted and reported as $\log$ CFU/g. For Salmonella, diluted sample $(1 \mathrm{~mL})$ was aseptically inoculated on a Petri dish containing $20 \mathrm{~mL}$ of tryptic soy agar yeast extract along with $0.05 \%$ ferric ammonium citrate and $0.03 \%$ sodium thiosulfate (Amanda et al., 2014). After that, the plate was allowed to solidify and was incubated at $35^{\circ} \mathrm{C}$ for $48 \mathrm{~h}$. Colonies were counted and are reported as $\log \mathrm{CFU} / \mathrm{g}$.

\section{Statistical analysis}

A completely randomized design was used in this study. Sampling and experiments were done in triplicates. Data shown are mean values with standard deviations. Oneway analysis of variance was carried out, and means comparisons were performed using Duncan's multiple range test. Statistical analysis was performed using SPSS (SPSS Inc., Chicago, IL, USA) for Windows.

\section{Results and Discussion}

\section{Color characteristics and physical dimensions}

Figure 1 shows the time profiles of color, height, diameter, and weight of the meringues in long-term storage in the various packages and the tested storage temperatures. Overall, this study discovered that the storage period and storage temperature substantially impacted the quality of the meringue. Typically, protein-rich products are susceptible to changes in color (Chevallier et al., 2000). The prolonged storage affects the color coordinates, including lightness, redness, and yellowness (Figure 1A-C). In a comparison of the treatments, the control samples showed significant changes in meringue color. The lightness and yellowness gradually decreased, while the redness steadily increased with storage, indicating that the meringues were affected by nonenzymatic browning reactions (Charoen et al., 2014). In comparison to the lower temperature storage, the higher temperature gave more browning to the samples. The differences in color changes between the treatments were minimal. However, the M-LDPE samples retained their color better and developed browning more slowly than the PET samples. On-nom et al. (2015) also reported a similar finding, as the prolonged storage decreased the color of samples when stored in PET more than with the M-LDPE package. Moisture and water activity of the samples play crucial roles in browning (Gonzalez, 2017). This study found that the range of water activity in samples was susceptible to the onset of the Maillard reaction. Bassey et al. (2013) also reported that water activity is the key factor in stored samples allowing activation of the browning-related reactions. The increase in the moisture level of bakery products or any dried products in a package depends on the water vapor transmission through the barrier package (Shakerardakani and Karim, 2012). When meringue samples were stored at the lower temperature, they retained their height and diameter (Figure 1D-E), which tended to decrease during storage. Prolonged storage had a noticeable effect on the height and diameter of the meringue. While no significant differences were observed between the various treatments, compared to control, substantial differences were observed. Abasi et al. (2009) reported that changes in the structure of baked food materials are mainly attributed to time and temperature. In addition, the choice of treatment had no discernible effect on the weight of meringues (Figure 1F). However, control samples held at either storage temperature had a gradual weight increase over time, albeit a relatively small increase. The increased weight in control samples could be due to sugar in the meringue recipe, which is hygroscopic and likely absorbs free moisture from the air while the sample firmness should be degraded.

\section{Moisture, water activity, and $\mathrm{pH}$}

Figure 2 shows the meringue moisture, water activity, firmness, and $\mathrm{pH}$ changes during storage in the alternative packages and at two temperatures. The moisture content of the samples steadily increased with time $(\mathrm{P}<0.05)$, and the water activity followed a similar pattern. In a comparison of the packages, the results indicate that meringue samples stored in paper packages at both temperatures were highly affected by the atmospheric moisture content (Figure 2A). In addition, the temperature was a significant factor affecting the changes in the meringue moisture content. Turan (2021) revealed that the moisture absorption of the food product through the package is significantly impacted by the rate of water vapor transmission, the thickness of the package, and the environment's relative humidity (RH). At the higher storage temperature, the elevated relative humidity in the environment increased the moisture transmission rate across the packaging material and the food product (Kurek et al., 2014). At temperatures above ambient, airier food products such as meringue absorb moisture 
(A)

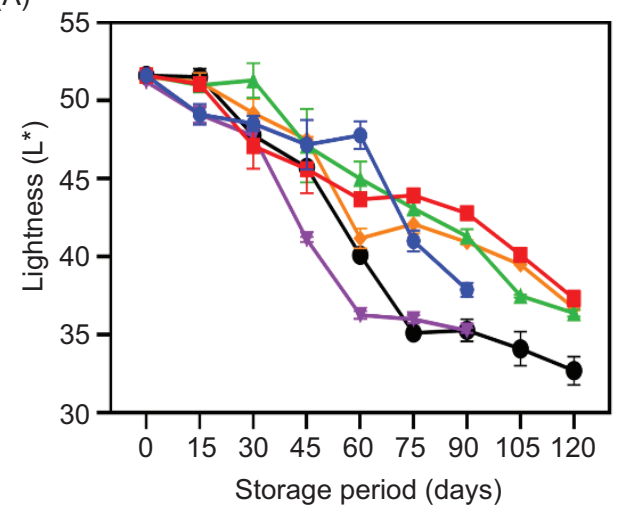

(B)

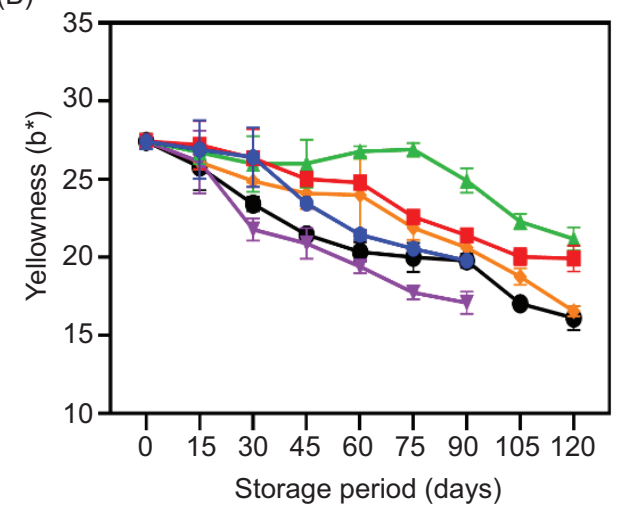

(C)

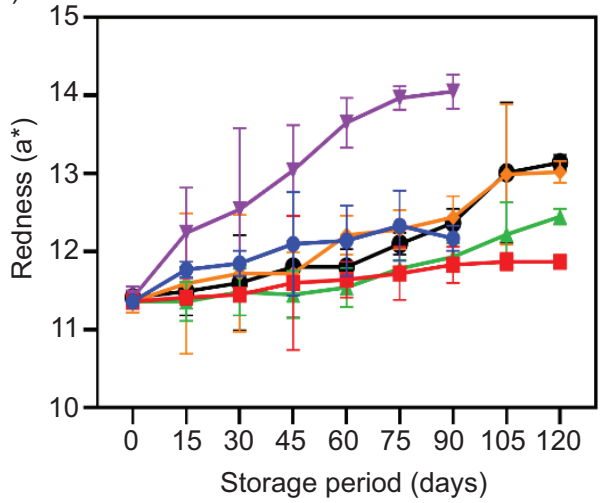

(D)

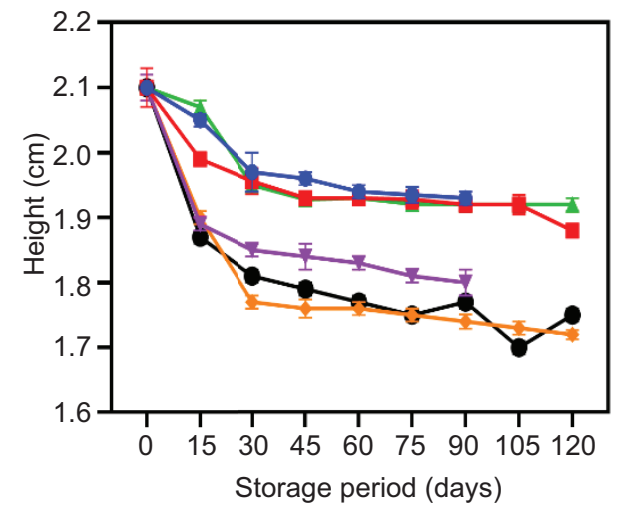

(E)

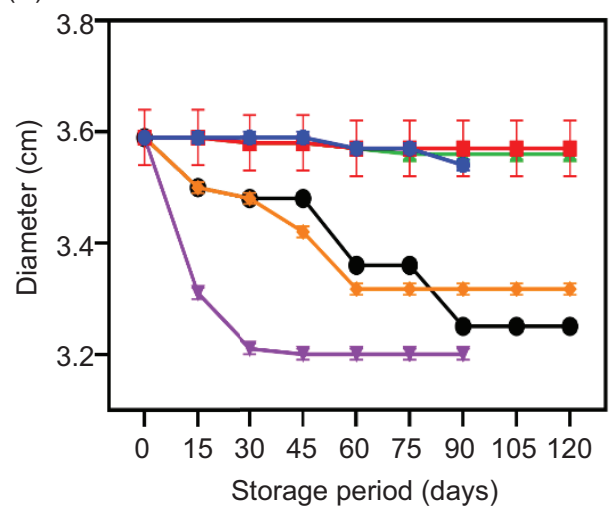

(F)

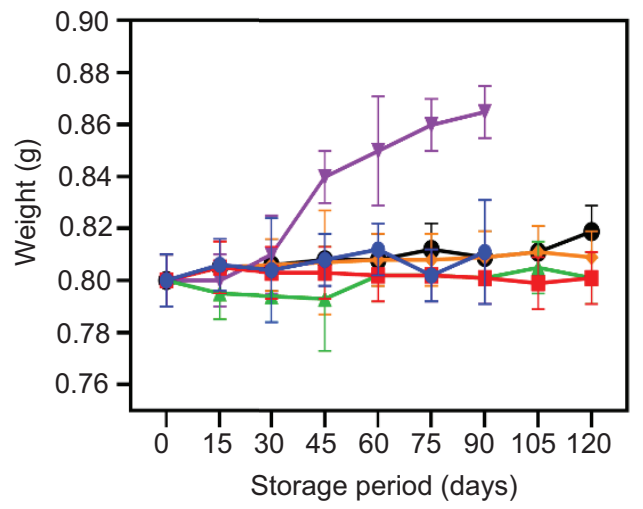

PET $-40^{\circ} \mathrm{C}$

Figure 1. Time traces of CIE-L*a* $\mathrm{b}^{*}$ color coordinates and physical dimensions of the meringue samples stored in alternative packages at two storage temperatures for a prolonged period.

faster than other products (Aviara, 2020). Water activity is one of the significant parameters associated with the shelf life via effects on storage stability, microbial growth, and rheological behavior of dehydrated food products (Syamaladevi et al., 2016; Yuceer, 2020). Yuceer (2020) has shown that prolonged storage of meringue elevated its water activity dramatically, mainly attributed to its high hygroscopic nature. The water activity of the control samples increased gradually over time, whereas the samples stored in M-LDPE and PET packages remained stable (Figure 2B). A steady increase in $\mathrm{pH}$ was observed in all samples stored in different packages and at different temperatures (Figure $2 \mathrm{C}$ ). The typical $\mathrm{pH}$ of meringue is 7.0 (Kim et al., 2016), but this study found that the addition of salted duck egg white slightly decreased the $\mathrm{pH}$ to 6.8. Storage temperature did not affect the $\mathrm{pH}$ changes 
(A)

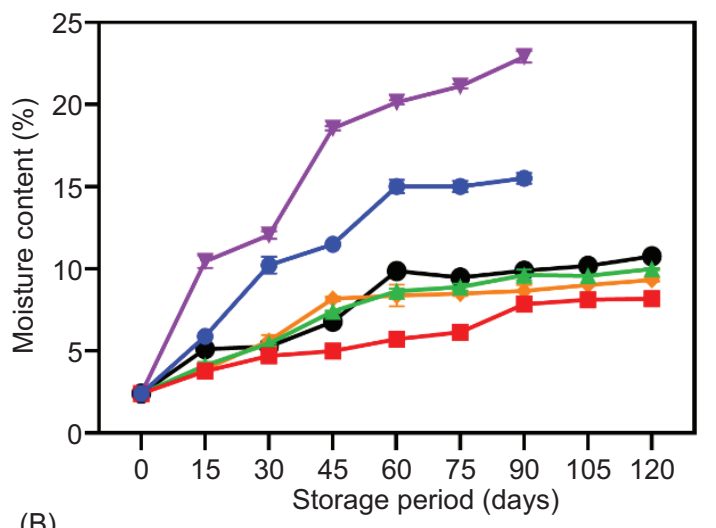

(B)

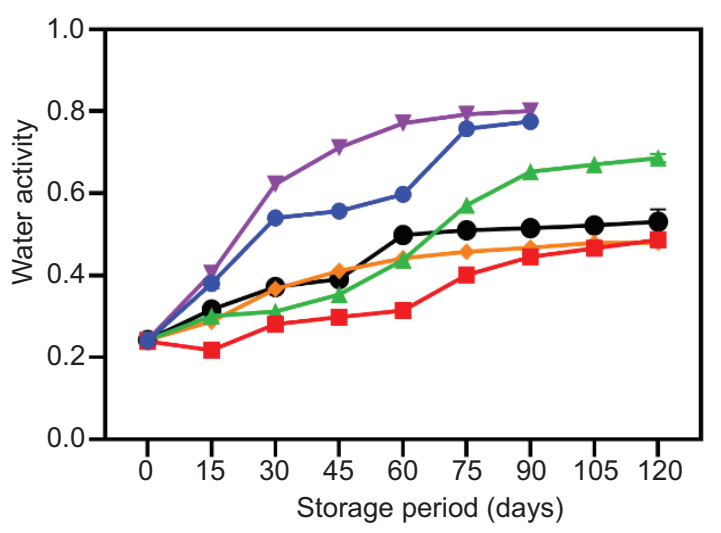

(C)

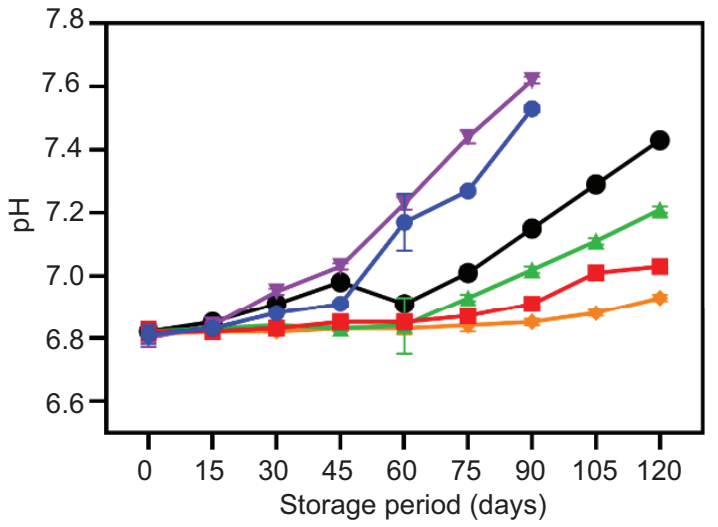

$\rightarrow$ Control $-30^{\circ} \mathrm{C} \rightarrow \mathrm{M}-\mathrm{LDPE}-30^{\circ} \mathrm{C} \rightarrow \mathrm{PET}-30^{\circ} \mathrm{C}$

$\rightarrow$ Control $-40^{\circ} \mathrm{C} \rightarrow \mathrm{M}-\mathrm{LDPE}-40^{\circ} \mathrm{C} \rightarrow \mathrm{PET}-40^{\circ} \mathrm{C}$

Figure 2. Time traces of moisture content, water activity, and $\mathrm{pH}$ of the meringue samples stored in alternative packages at two storage temperatures for a prolonged period.

much, although a slight increase was noted, especially in the control samples when stored at $40^{\circ} \mathrm{C}$. M-LDPE maintained a lower $\mathrm{pH}$ than the other packages during extended storage at either tested storage temperature. Bell (1995) found that increased or decreased water activity in food could adversely affect the food $\mathrm{pH}$.

\section{Textural characteristics}

Figure 3 shows the time profiles of textural characteristics of meringues stored in the different packages and at two temperatures. The amount of force required to compress food products by a certain amount is referred to as hardness (Singh et al., 2015). The hardness in all cases tended to decrease throughout storage. Control samples had the most severe loss of firmness, followed by M-LDPE and PET samples (Figure 3A). The lower temperature retained firmness better than the higher temperature. The differences in the sample's hardness could be caused by the absorption of moisture. Firmness is directly related to density, viscosity, surface tension, and other physical features of the food product (Day and Golding, 2016; Pascua et al., 2013). The water activity and the specific volume could significantly impact the firmness of the meringue over prolonged storage. The adhesiveness of the meringue increased with storage time, and the control samples had higher adhesiveness than the others (Figure 3B). Storage temperature significantly impacted the adhesiveness of the meringues in the control package, whereas it did not affect samples in M-LDPE and PET packages. On the other hand, the chewiness and cohesiveness decreased with storage time (Figure 3C-D). Samples in the M-LDPE and PET packages retained chewiness and cohesiveness better, whereas the control samples significantly lost those attributes. Storage temperature and storage period significantly affected these values, and the control samples had lower chewiness when stored at $30^{\circ} \mathrm{C}$ and slightly higher cohesiveness when stored at $40^{\circ} \mathrm{C}$. Moisture content could adversely influence the textural properties. GrigelmoMiguel et al. (1999) reported that textural properties, particularly the chewiness, were adversely affected by the moisture content in muffins. Wada et al. (2017) reported that hardness, cohesiveness, and adhesiveness shared a similar trend in baked food products. The fracturability of meringue indicates the ease of breaking and decreases gradually with the storage time (Figure 3E). Storage temperature and packaging material did not significantly affect the meringue's fracturability. Singh et al. (2015) reported that baked food products enriched with fiber exhibited more fracturability than protein-rich products. On the other hand, the gumminess of the meringue gradually decreased with storage time (Figure 3F). The control samples lost more gumminess than the other cases, and there were no significant differences among the treatments. Storage temperature did not influence the meringue's gumminess much. Resilience indicates the ability of a food product to retain its original shape. The results showed that increased storage time increased the resilience of the meringue (Figure 3G). The control samples had the least resilience, less than M-LDPE and PET packaged samples. Furthermore, the temperature did not affect the meringue's resilience. On the other hand, 
(A)

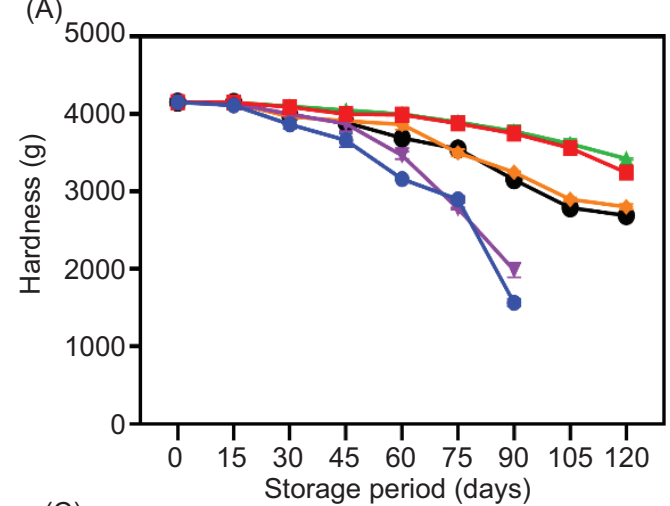

(C)

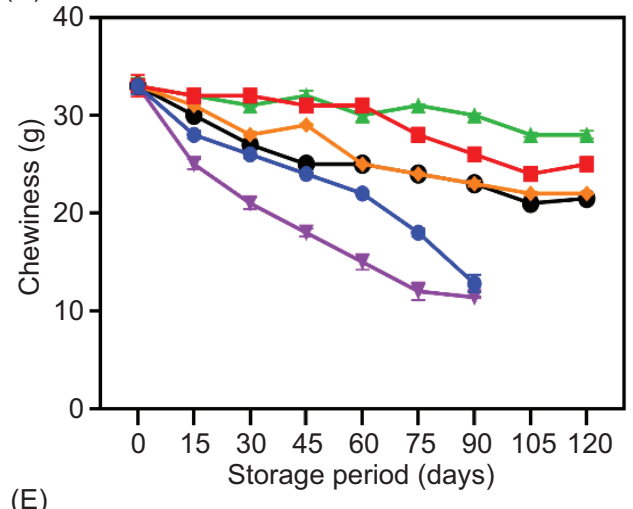

(E)

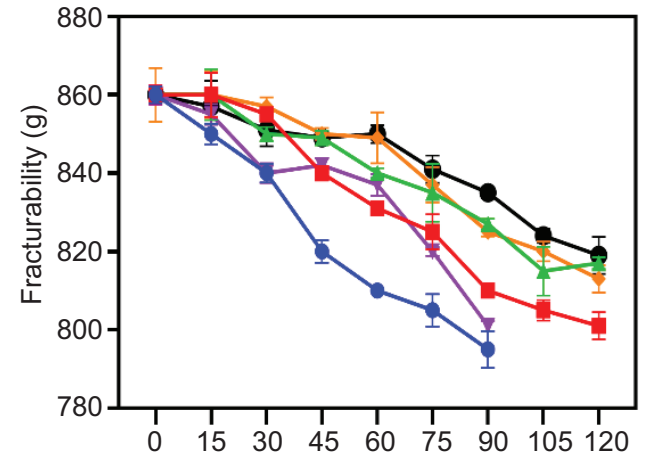

(G)

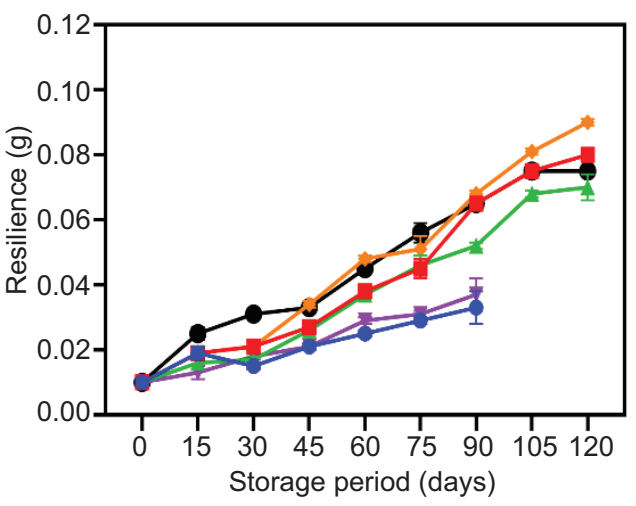

(B)

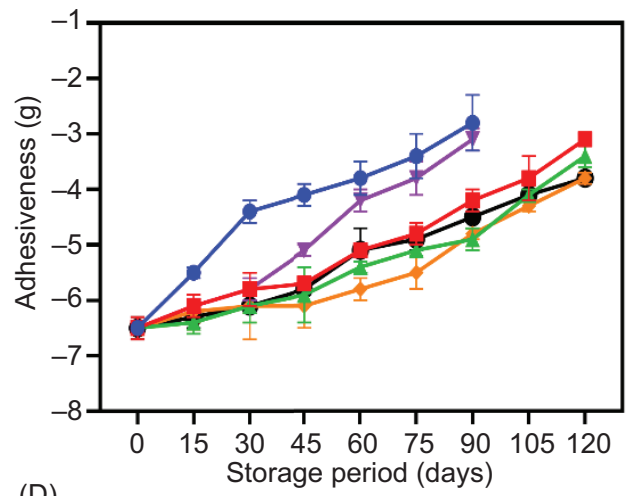

(D)

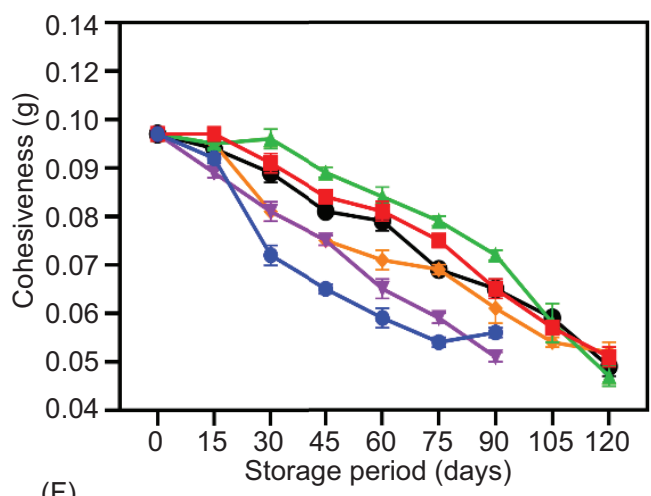

(F)

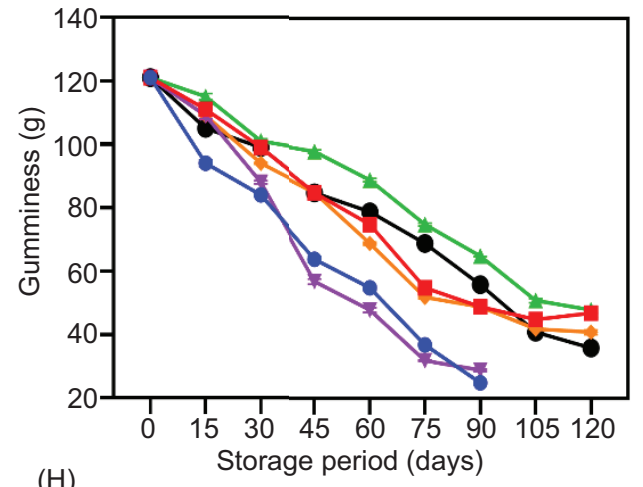

(H)

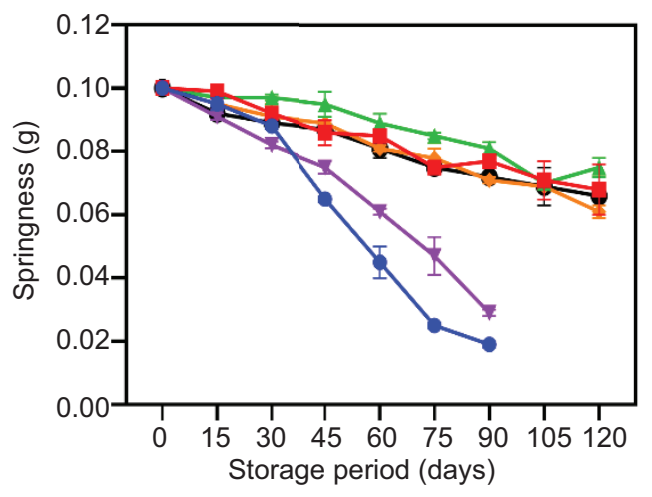

$\rightarrow$ Control $-30^{\circ} \mathrm{C} \rightarrow \mathrm{M}-\mathrm{LDPE}-30^{\circ} \mathrm{C} \rightarrow \mathrm{PET}-30^{\circ} \mathrm{C} \rightarrow \mathrm{Control}-40^{\circ} \mathrm{C} \rightarrow \mathrm{M}-\mathrm{LDPE}-40^{\circ} \mathrm{C} \rightarrow \mathrm{PET}-40^{\circ} \mathrm{C}$

Figure 3. Time traces of textural characteristics of the meringue samples stored in alternative packages at two storage temperatures for a prolonged period. 
the springiness of meringues gradually decreased with storage duration, and the samples in M-LDPE and PET packages did not differ much during the storage and were not affected by the storage time (Figure $3 \mathrm{H}$ ). In contrast, the control samples significantly lost springiness, and the samples stored at $30^{\circ} \mathrm{C}$ were more affected. Yuceer and Asik (2020) reported that prolonged storage significantly affected meringue's rheological and textural properties.

\section{Antioxidant activities}

Figure 4 illustrates the antioxidant activity of meringues held for an extended period in alternative packages at two temperatures. Overall, a sharp rise in antioxidant activity was seen in the meringues in all cases. Prolonged storage considerably affected the radical scavenging activity. The storage temperature significantly affected antioxidant properties, particularly DPPH radical scavenging, hydroxyl radical scavenging, and ferrous ion chelating activities. All meringue samples showed a linear trend in increasing DPPH radical scavenging activity (87-96\%) (Figure 4A). In comparison to the other antioxidant activities, DPPH radical scavenging activity was the highest. The control samples had significantly less scavenging activity than samples in the actual treatments. The samples held in the M-LDPE package at both temperatures had increasing DPPH scavenging activity, followed by samples in PET packages. Storage temperature had no significant impact on the meringue's DPPH radical scavenging abilities; however, for samples stored at $30^{\circ} \mathrm{C}$, the DPPH radical scavenging somewhat increased. Similarly, the hydroxyl radical scavenging activity (81-89\%) and ABTS radical scavenging activity (55-67\%) in meringue increased gradually with storage time (Figure $4 \mathrm{~B}-\mathrm{C}$ ), and prolonged storage significantly increased these activities in the meringues, while the choice of packaging material and storage temperature did not affect them. Toward the end of storage, meringue samples stored in the PET package at either storage temperature had slightly higher hydroxyl and ABTS radical scavenging activities than the other cases. On the other hand, the ferrous
(A)

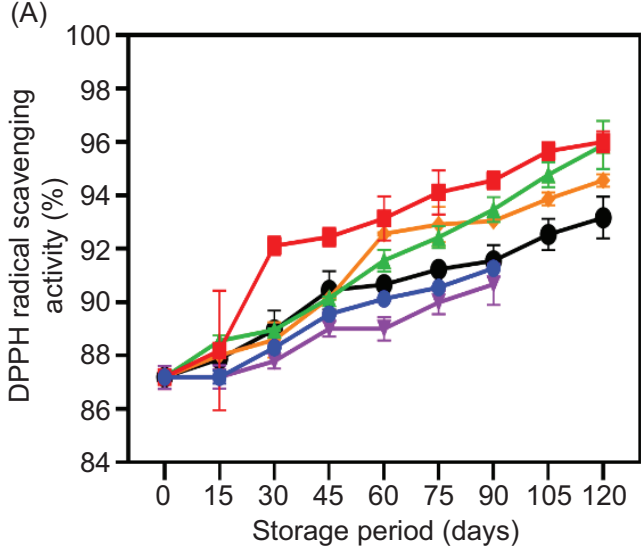

(C)

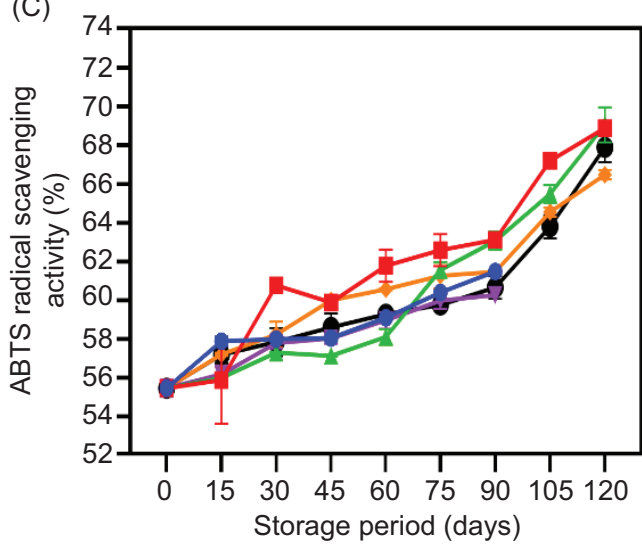

(B)

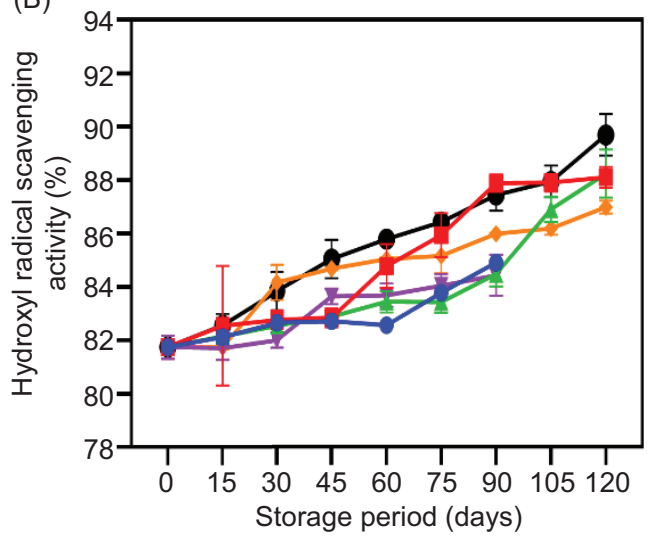

(D)

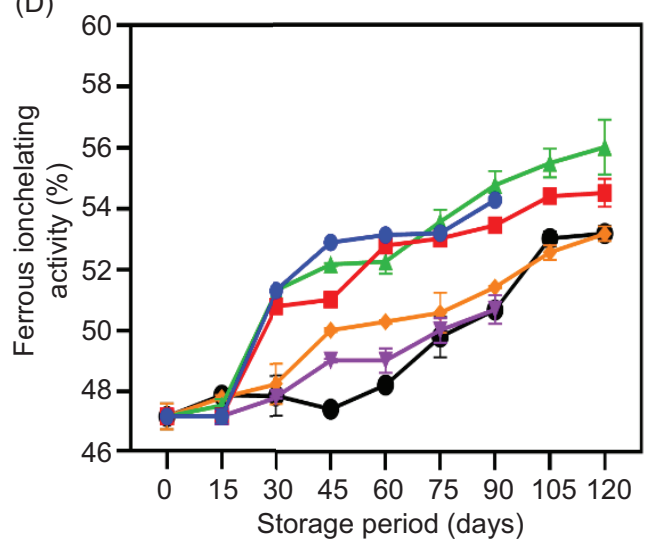

$\rightarrow$ Control $-30^{\circ} \mathrm{C} \rightarrow \mathrm{M}-\mathrm{LDPE}-30^{\circ} \mathrm{C} \neq \mathrm{PET}-30^{\circ} \mathrm{C} \rightarrow \mathrm{Control}-40^{\circ} \mathrm{C} \rightarrow \mathrm{M}-\mathrm{LDPE}-40^{\circ} \mathrm{C} \rightarrow \mathrm{PET}-40^{\circ} \mathrm{C}$

Figure 4. Time traces of various radical scavenging abilities of the meringue samples stored in alternative packages at two storage temperatures for a prolonged period. 
ion chelating activities (47-56\%) of meringue samples showed considerably different trends. While there was a continual increase in the chelating activity, it was the smallest compared to the other radical scavenging activities in this investigation (Figure 4D). After 30 days of storage, a noticeable trend was observed in the ferrous ion chelating activity of samples, such that the meringue samples stored at $30^{\circ} \mathrm{C}$ showed a higher ferrous ion chelating activity than the samples stored at $40^{\circ} \mathrm{C}$. The PET-packaged samples demonstrated more significant chelating activity than the M-LDPE-packaged samples when stored at $30^{\circ} \mathrm{C}$, but this trend was not consistent at $40^{\circ} \mathrm{C}$. Typically, eggs and egg-related products contain high-quality proteins such as ovalbumin, ovotransferrin, cystatin, and phosvitin, all of which have demonstrated significant antioxidant activity (Nimalaratne and Wu, 2015). Charoen et al. (2014) revealed that meringues have high antioxidant activity, attributed to melanoidin and D-ketohexoses, and found greater concentrations in the baked meringues. Kim et al. (2016) reported that meringues had a high level of total phenolics, which is widely regarded as an antioxidant source. According to Devi et al. (2015), coconut sugar contains a high level of ascorbic acid and polyphenolic contents. Coconut sugar was employed as a component in the meringue in this study, which may have contributed to the antioxidant activity of the samples. Purlis (2010) found a continuous development of condensation and polymerization via the Maillard reaction in samples during storage, owing to the sample's high amino acid and sugar contents and their $\mathrm{pH}$, which are optimal for Maillard reactions. This is consistent with the findings of the current investigation.

\section{Microbial growth}

Figure 5 shows the time profiles of microbiological growth in meringues stored in different packages and at two storage temperatures. At both temperatures, considerable microbial growth was seen in the control samples;
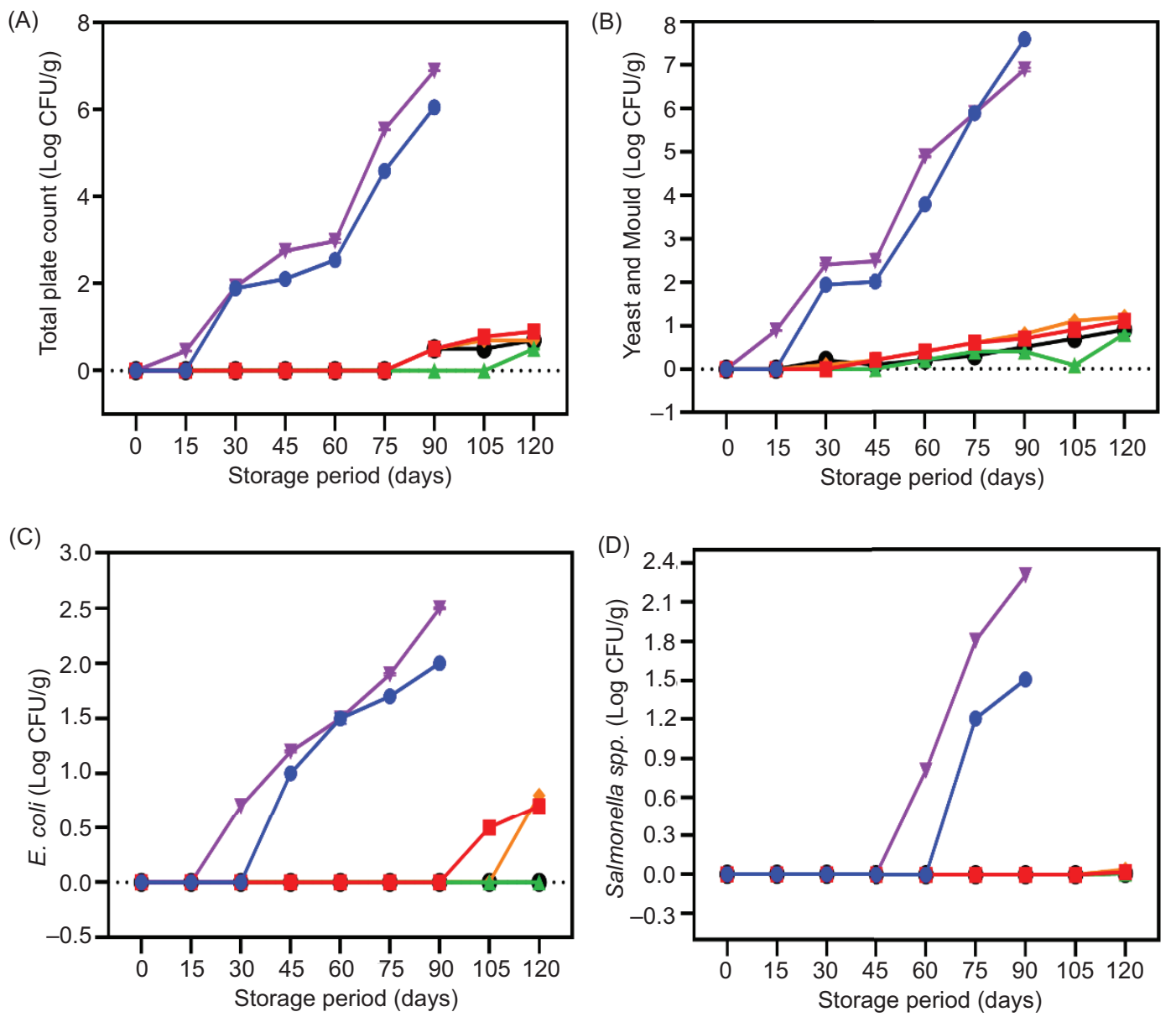

$\rightarrow$ Control $-30^{\circ} \mathrm{C} \rightarrow \mathrm{M}-\mathrm{LDPE}-30^{\circ} \mathrm{C} \rightarrow \mathrm{PET}-30^{\circ} \mathrm{C} \rightarrow \mathrm{Control}-40^{\circ} \mathrm{C} \rightarrow \mathrm{M}-\mathrm{LDPE}-40^{\circ} \mathrm{C}$ PET $-40^{\circ} \mathrm{C}$

Figure 5. Time traces of microbial activity in the meringue samples stored in alternative packages at two storage temperatures for a prolonged period. 
although there were no significant differences between the control samples, and those held at $40^{\circ} \mathrm{C}$ exhibited slightly higher microbial growth. The total plate counts of the meringue samples demonstrated that M-LDPE and PET packages could maintain the samples without microbial growth (Figure 5A), although after 60 days of storage, a slight onset of microbial growth was also found in these samples. However, the growth remained within acceptable bounds. Similarly, yeast and mold proliferation were extremely high in the control samples and lesser in those packaged in M-LDPE and PET (Figure 5B). In comparison to PET, M-LDPE packages gave slightly greater yeast and mold growth. The PET package may limit oxygen transport, thereby limiting the yeast and mold growth in meringues during storage. Among the many microorganisms found in bread products, mold is known to be the primary cause of deterioration. Low moisture content, water activity, and $\mathrm{pH}$ of baked food products may inhibit bacterial development (Guynot et al., 2005a, 2005b), while yeast and molds remain unaffected. Saeed et al. (2018) revealed that mold was more prominent in bakery products than yeast during storage. This could be due to the low moisture and water activity requirements for mold, whereas the requirements are higher for the growth of yeast. In addition, Salmonella and E. coli were also detected in meringue samples during the storage (Figure 5C-D). E. coli was observed in the control samples from day 15 onward, whereas the M-LDPE and PET packages successfully eliminated the growth of E.coli for most of the storage period. Samples held at $30^{\circ} \mathrm{C}$ had lesser E. coli growth than those stored at $40^{\circ} \mathrm{C}$. Similarly, Salmonella development was seen in meringues stored for an extended period, particularly in control samples. In contrast, no Salmonella was observed in the M-LDPE and PET packaged samples at either temperature. Podolak et al. (2010) reported that Salmonella and E.coli are potential pathogens seen in food products baked in low moisture. According to $\mathrm{Wu}$ (2016), pathogenic bacteria can survive in extreme conditions, and under stressful conditions, they adapt by activating stress-induced responses (narZ, dadA, stiC, and rpoS), allowing them to survive in the long-term storage.

\section{Conclusion}

Salted duck egg white meringues showed good resistance against deterioration during prolonged storage. The alternative packages and storage temperatures played significant roles in the changes in meringue quality. The color of the meringue was significantly affected by the duration of storage. The higher $40^{\circ} \mathrm{C}$ storage temperature increased the browning of the samples compared with the lower $30^{\circ} \mathrm{C}$ temperature. Meringues also had a gradual weight increase with storage time at higher temperatures. Meringue samples stored in the control package with poor barrier properties were strongly impacted by the absorption of atmospheric moisture at both temperatures. The firmness of all samples tended to decrease throughout storage. Meringues exhibited the highest DPPH radical scavenging activity as compared to the other radical scavenging activities. Choice of packaging material or storage temperature did not significantly impact the meringue's radical scavenging abilities. Microbial growth significantly impacted the meringue's shelf life, especially for the control samples. Samples stored at $30^{\circ} \mathrm{C}$ had slightly less $E$. coli growth than those at $40^{\circ} \mathrm{C}$. Salmonella and E. coli were also observed in the meringues during storage, but only minimally compared with yeast and mold growth. Control samples were severely affected by microbial growth, whereas the M-LDPE and PET packaged cases had only very minimal growth. This study concludes that M-LDPE and PET packages are well suited for packaging meringue for a prolonged storage period, and storage below $40^{\circ} \mathrm{C}$ would help retain the quality for a longer time.

\section{Acknowledgment}

The authors are grateful to Research and Development Organization, Prince of Songkla University, Hatyai Campus, for funding this study (Project Grant No. SIT601320S). In addition, the authors would like to thank the Prince of Songkla University, Surat Thani Campus, for providing extra financial support in 2016. The Food Innovation and Product Development (FIPD) Laboratory is thanked for providing laboratory space and equipment.

\section{Conflict of Interest}

The authors have declared no conflict of interest in the submission of this article.

\section{References}

Abasi, S., Mousavi, S.M., Mohebi, M. and Kiani, S., 2009. Effect of time and temperature on moisture content, shrinkage, and rehydration of dried onion. Iranian Journal of Chemical Engineering 6(3): 57-70.

Amanda, A.L., Taylor, T. and Schnepf, J., 2014. Survival of Salmonella during baking of peanut butter cookies. Journal of Food Protection 77(4): 635-639. https://doi.org/10.4315/0362028X.JFP-13-4.08

American Public Health Association, 1978. Standard methods for the examination of dairy products. 14th ed. APHA Inc., Washington, DC.

Amit, K.S., Uddin, M., Rahman, R., Islam, R.M.S. and Khan, S., 2017. A review on mechanisms and commercial aspects of food 
preservation and processing. Agriculture \& Food Security 6(51): 1-22. https://doi.org/10.1186/s40066-017-0130-8

Andrady, L.A. and Neal, A.M., 2009. Application and societal benefits of plastics. Philosophical Transactions of the Royal Society B: Biological Sciences 364: 1977-1984. https://doi. org/10.1098/rstb.2008.0304

Association of Official Analytical Chemists (AOAC), 2002. Official methods of analysis. 16th ed. Association of Official Analytical Chemists, Washington, DC.

Association of Official Analytical Chemists (AOAC), 2003. AOAC official methods of analysis 17th ed. J. AOAC. International, Gaithersburg, MD.

Aviara, A.N., 2020. Moisture sorption isotherms and isotherm model performance evaluation for food and agricultural products. In: Kyzas, G. and Lazaridis, N. (eds.) Sorption in 2020s. Intech Open, London.

Bassey, F.I., Chinnan, M.S., Ebenso, E.E., Edem, C.A. and Iwegbue, C.M.A., 2013. Color change: an indicator of the extent of Maillard browning reaction in food system. Asian Journal of Chemistry 25(16): 9325-9328. https://doi.org/10.14233/ ajchem.2013.15504

Bastarrachea, L., Dhawan, S. and Sablani, S.S., 2011. Engineering properties of polymeric based antimicrobial films for food packaging. Food Engineering Revision 3: 79-93. https://doi. org/10.1007/s12393-011-9034-8

Bell, N.L., 1995. Kinetics of non-enzymatic browning in amorphous solid systems: distinguishing the effects of water activity and the glass transition. Food Research International 28(6): 591-597. https://doi.org/10.1016/j.foodchem.2007.11.057

Bennion, E.B., Bamford, G.S.T. and Bent, A.J., 1997. Eggs and egg products. In: Bent A.J. (ed.) The technology of cake making. Springer, Boston, MA, pp. 18-24.

Brand-Williams, W., Cuvelier, M.E. and Berset, C., 1995. Use of a free radical method to evaluate antioxidant activity. LWT-Food Science and Technology 28(1): 25-30. https://doi.org/10.1016/ S0023-6438(95)80008-5

Charoen, O.S., Hayakawa, S. Matsumoto, Y. and Ogawa, M., 2014. Effect of D-Psicose used as sucrose replacer on the characteristics of meringue. Journal of Food Science 79(12): 2463-2469. https://doi.org/10.1111/1750-3841.12699

Chevallier, S., Colona, P., Buleon, A. and Valle, D.G., 2000. Physicochemical behaviors of sugars, lipids, and gluten in short dough and biscuit. Journal of Agricultural and Food Chemistry 48(4): 1322-1326. https://doi.org/10.1021/jf990435+

Chi, S.P. and Tseng, K.H., 1998. Physicochemical properties of salted pickled yolks from duck and chicken eggs. Journal of Food Science 63(1): 27-30. https://doi.org/10.1111/j.1365-2621.1998. tb15668.x

Day, L. and Golding, M., 2016. Food structure, rheology, and texture, In: Melton, L., Shahidi, F. and Varelis, P. (eds) Encyclopedia of food chemistry. Academic Press, Baltimore, MA, pp. 125-129.

Devi, S.N., Hariprasad, T., Ramesh, K. and Merugu, R., 2015. Antioxidant properties of coconut sap and its sugars. International Journal of PharmTech Research 8(1): 160-162.

Gonzalez, S.P.F., 2017. The effect of storage temperatures and time on the quality of spray dried egg powder. LSU Master's
Theses. 4583. Available at: https://digitalcommons.lsu.edu/ gradschool_theses/4583

Grigelmo-Miguel, N., Carreras-Boladeras, E. and MartinBelloso, O., 1999. Development of high-fruit-dietary-fibre muffins. European Food Research and Technology 210: 123-128. https://doi.org/10.1007/s002170050547

Guynot, E., Marin, S.M., Sanchis, V. and Ramos, A., 2005a. Low intermediate moisture bakery product by Mudelling Eurotium sp. Aspergillus sp. and Penicillium corylophilum growth. International Journal of Food Microbiology 101: 169-177. https://doi.org/10.1016/j.ijfoodmicro.2004.11.002

Guynot, M.E., Ramos, A., Sanchis, V. and Marin, S., 2005b. Study of benzoate, propionate and sorbate salts as mould spoilage inhibitors on intermediate moisture bakery products of low $\mathrm{pH}$ (4.55.5). International Journal of Food Microbiology 10(2): 161-168. https://doi.org/10.1016/j.ijfoodmicro.2004.11.003

Halliwell, B., Gutteridge, J.M.C. and Aruoma, O.I., 1987. The deoxyribose method: a simple "test-tube" assay for determination of rate constants for reactions of hydroxyl radicals. Analytical Biochemistry 165: 215-219. https://doi. org/10.1016/0003-2697(87)90222-3

Kim, K., Kim, Y. and Hong, M., 2016. Quality characteristics of meringue cookies added with tomato powder. Journal of the Korean Society of Food Science and Nutrition 45(3): 366-371. https://doi.org/10.3746/jkfn.2016.45.3.366

Kurek, M., Guinault, A., Voilley, A., Galic, K. and Debeaufort, F., 2014. Effect of relative humidity on carvacrol release and permeation properties of chitosan-based films and coating. Food Chemistry 144: 9-17. https://doi.org/10.1016/j. foodchem.2012.11.132

Lai, K.M., Chi, S.P. and Ko, W.C., 1999. Changes in yolk states of duck egg during long-term brining. Journal of Agricultural and Food Chemistry 47:733-736. https://doi.org/10.1021/jf980486r

Lee, K.K., Oh, C.Y., Cho, K.W. and Ma, Y.J., 2015. Antioxidant and anti-inflammatory activity determination of one hundred kinds of pure chemical compounds using offline and online screening HPLC assay. eCAM 165457: 1-13. https://doi. org/10.1155/2015/165457

Lekjing, S. and Venkatachalam, K., 2021. Changes in physicochemical characteristics, polyphenolics, and amino acids of wax apple cider vinegar during prolonged storage. Italian Journal of Food Science 33(2): 129-141. https://doi.org/10.15586/ijfs.v33i2.2049

Lomakina, K. and Mikova, K., 2006. A study of the factors affecting the foaming properties of egg white - a review. Czech Journal of Food Science 24(3): 110-118. https://doi. org/10.17221/3305-CJFS

Marsh, K. and Bugusu, B., 2007. Food packaging - roles, materials, and environmental issues. Journal of Food Science 72(3): 39-55. https://doi.org/10.1111/j.1750-3841.2007.00301.x

Nimalaratne, C. and Wu, J., 2015. Hen egg as an antioxidant food commodity. Nutrients 7: 8274-8293. https://doi. org/10.3390\%2Fnu7105394

On-nom, N., Nualkaekul, S., Sinchaipanit, P., Murtaza, A.M. and Chalermchaiwat, P., 2015. Effect of packaging films on the quality and storage stability of cheese shake biscuits made from germinated Hom Nin Brown rice flour with sugar-reduced 
pineapple paste filing. Journal of Science and Technology, Ubon Ratchathani University 17(1): 91-96.

Pascua, Y., Koc, H. and Foegeding, E.A., 2013. Food structure: roles of mechanical properties and oral processing in determining sensory texture of soft materials. Current Opinion in Colloid and Interface Science 18(4): 324-333. https://doi.org/10.1016/j. cocis.2013.03.009

Podolak, R., Enache, E., Stone, W., Black, D.G. and Elliott, P.H., 2010. Sources and risk factors for contamination, survival, persistence, and heat resistance of Salmonella in low-moisture foods. Journal of Food Protection 73: 1919-1936. https://doi. org/10.4315/0362-028x-73.10.1919

Punidadas, P. and McKellar, R.C., 1999. Selected physical properties of liquid egg products at pasteurization temperatures. Journal of Food Processing and Preservation 23: 153-168. https://doi. org/10.1111/j.1745-4549.1999.tb00376.x

Purlis, E., 2010. Browning development in bakery products - a review. Journal of Food Engineering 99(3): 239-249. https://doi. org/10.1016/j.jfoodeng.2010.03.008

Rawat, S., 2015. Food spoilage: microorganisms and their prevention. Asian Journal of Plant Science and Research 5(4): 47-56.

Saeed, I., Shaheen, S., Hussain, K., Khan, A.M., Jaffer, M., Mahmood, T., Khalid, S., Sarwar, S., Tahir, A. and Khan, F., 2018. Assessment of mold and yeast in some bakery products of Lahore, Pakistan based on LM and SEM. Microscopy Research and Technique 82(2): 85-91. https://doi.org/10.1002/jemt.23103

Saranraj, P. and Geetha, M., 2012. Microbiological spoilage of bakery products and its control by preservatives. International Journal of Pharmaceutical and Biological Archives 3(1): 38-48.

Shakerardakani, A. and Karim, R., 2012. Effect of different types of plastic packaging films on the moisture and aflatoxin contents of pistachio nuts during storage. Journal of Food Science and Technology 50(2): 409-411. https://doi.org/10.1007/ s13197-012-0624-0

Singh, N. and Rajini, P.S., 2004. Free radical scavenging activity of an aqueous extract of potato peel. Food Chemistry 85: 611-616. https://doi.org/10.1016/j.foodchem.2003.07.003

Singh, P., Singh, R., Jha, A., Rasane, P. and Gautam, K.A., 2015. Optimization of a process for high fibre and high protein biscuit. Journal of Science and Technology 52(3): 1394-1403. https:// doi.org/10.1007/s13197-013-1139-z

Syamaladevi, M.R., Tang, J., Villa-Rojas, R., Sablani, S., Carter, B. and Campbell, G., 2016. Influence of water activity on thermal resistance of microorganisms in low-moisture foods: a review. Comprehensive Reviews 15(2): 353-370. https://doi. org/10.1111/1541-4337.12190
Turan, D., 2021. Water vapor transport properties of polyurethane films for packaging of respiring foods. Food Engineering Reviews 13: 54-65. https://doi.org/10.1007/s12393-019-09205-z Venkatachalam, K., 2018. Influence of prolonged salting on the physiochemical properties of duck egg white. Brazilian Archives of Biology and Technology 61: e18180134. https://doi. org/10.1590/1678-4324-2018180134

Wada, S., Goto, T., Fujimoto, K., Watanabe, M., Nagao, K., Nakamichi, A. and Ichikawa, T., 2017. Changes in food bolus texture during mastication. Journal of Texture Studies 48: 171177. https://doi.org/10.1111/jtxs.12228

Wang, H.T., 2017. Slating yolks directly using fresh duck egg yolks with salt and maltodextrin. Journal of Poultry Science 54(1): 97-102. https://doi.org/10.214.1/jpsa.0160027

Wu, S., 2016. Survival of pathogens in cookie dough during storage and comparison of detection assays for pathogens in cookie dough. Doctor of Philosophy Thesis, University of Florida.

Xiao, G., Chen, Y., Fang, R., Xiao, C., Yuan, H., Chu, B., Liu, X. and Gong, J., 2019. Salt-tolerant Staphylococcus bacteria induce structural and nutritional alterations of salted duck egg white. Food Science and Nutrition 7: 3941-3949. https://doi. org/10.1002/fsn3.1255

Xu, L., Zhao, Y., Xu, M., Yao, Y., Nie, X., Du, H. and Tu, Y., 2017. Effects of salting treatment on the physicochemical properties, textural properties, and microstructures of duck eggs. PLoS One 12(8): e0182912. https://doi.org/10.1371/journal.pone.0182912

Yuceer, M., 2020. Evaluation of physicochemical properties on meringue prepared from phospholipase A2 enzyme-hydrolyzed liquid egg albumen. European Food Research and Technology 246: 1874-1856. https://doi.org/10.1007/s00217-020-03538-4

Yuceer, M. and Asik, H., 2020. Texture, rheology, storage stability and sensory evaluation of meringue's prepared from lipase enzyme-modified liquid egg white. Journal of Food Processing and Preservation 44(9): e14667. https://doi.org/10.1111/ jfpp.14667

Yuceer, M. and Caner, C., 2021. Effect of protease-hydrolyzed egg white on the meringue batter properties and meringue textural and sensory properties during storage. International Journal of Gastronomy and Food Science 25: 100409. https://doi. org/10.1016/j.ijgfs.2021.100409

Zoulias, E.I., Piknis, S. and Oreopoulou, V., 2000. Effect of sugar replacement by polyols and acesulfane- $\mathrm{K}$ on properties of low-fat cookies. Journal of the Science of Food and Agriculture 80: 2049-2056. https://doi.org/10.1002/10970010(200011)80:14<2049:AID-JSFA735>3.0.CO;2-Q 